\title{
Deceptive Endoscopic Appearances in Ulcerative Colitis
}

\author{
Jainudeen K.A. Jameel ${ }^{a}$ Tariq Ahmed ${ }^{a}$ Alastair MacDonald ${ }^{b}$ \\ John E. Hartley ${ }^{\mathrm{a}}$ \\ ${ }^{a}$ Academic Surgical Unit, University of Hull, and ${ }^{b}$ Department of Pathology Castle Hill Hospital, Cottingham, UK
}

Colonoscopy is widely used in the evaluation of ulcerative colitis [1, 2]. Its role in obtaining biopsies for detection of colorectal cancers (CRC) is well established; however, the differentiation between neoplastic and non-neoplastic lesions on macroscopic visualisation remains difficult.

A 49-year-old male was referred for suspected CRC because of symptoms of intermittent rectal bleeding and increasing stool frequency of 12 months duration. He gave a remote history of injection sclerotherapy for haemorrhoids followed by formal haemorrhoidectomy. The latter was undertaken without any colonic evaluation. $\mathrm{He}$ denied any family history of CRC or polyps. Clinical examination was normal. Urgent colonoscopy showed a 15-mm sessile polyp in mid-sigmoid which was snared and a lesion in the splenic flexure (fig. 1) with the macroscopic appearances of an annular cancer which was biopsied. The mucosa between these lesions appeared normal.

CT abdomen and pelvis performed for pre-operative staging of presumed splenic flexure carcinoma revealed concentric bowel thickening at the splenic flexure consistent with CRC with radiological staging of T2/T3, N0, M0. However, the biopsy of the lesion was reported as 'acute or chronic inflammatory bowel disease' (ulcerative colitis). So the patient underwent repeat colonoscopy. Macroscopic appearances were essentially unchanged. Random biopsies were performed from nor- mal-looking mucosa of ascending, transverse, descending and sigmoid colon. These were also reported as ulcerative colitis. Because of the presence of a lesion which appeared grossly malignant endoscopically and confirmed radiologically, with evidence of microscopic colitis throughout the colon, a total abdominal colectomy was performed. Patient experienced an uneventful postoperative period. Pathological examination of the resected specimen (fig. 2) confirmed ulcerative colitis and the lesion in the splenic flexure which appeared malignant on colonoscopy was reported as a confluence of inflammatory polyps.

\section{Discussion}

Colonoscopy is widely regarded as the procedure of choice in the diagnosis and assessment of ulcerative colitis $[1,2]$. The earliest mucosal abnormality is loss of vascular pattern due to mucosal oedema which obscures sub-mucosal vessels. More severe changes include erythema, contact bleeding, frank ulceration and pseudopolyps [3]. There is evidence to support concordance amongst endoscopists in the diagnosis of mucosal ulcerative colitis [4]; however, the differentiation of neoplastic from non-neoplastic lesions on macroscopic visualisation may be problematical. Colonoscopy after dyespraying of the lesions and visualizing the crypt pattern

\section{KARGER \\ Fax +4161306 1234 E-Mailkarger@karger.ch} www.karger.com
(C) 2005 S. Karger AG, Basel 0253-4886/05/0223-0149\$22.00/0

Accessible online at:

www.karger.com/dsu
Mr. J.E. Hartley

Senior Lecturer/Honorary Consultant Surgeon, University of Hull

Academic Surgical Unit, Castle Hill Hospital

Cottingham HU16 5JQ (UK)

Tel. +44 1482 622393, Fax +44 1482 623274, E-Mail J.E.Hartley@hull.ac.uk 


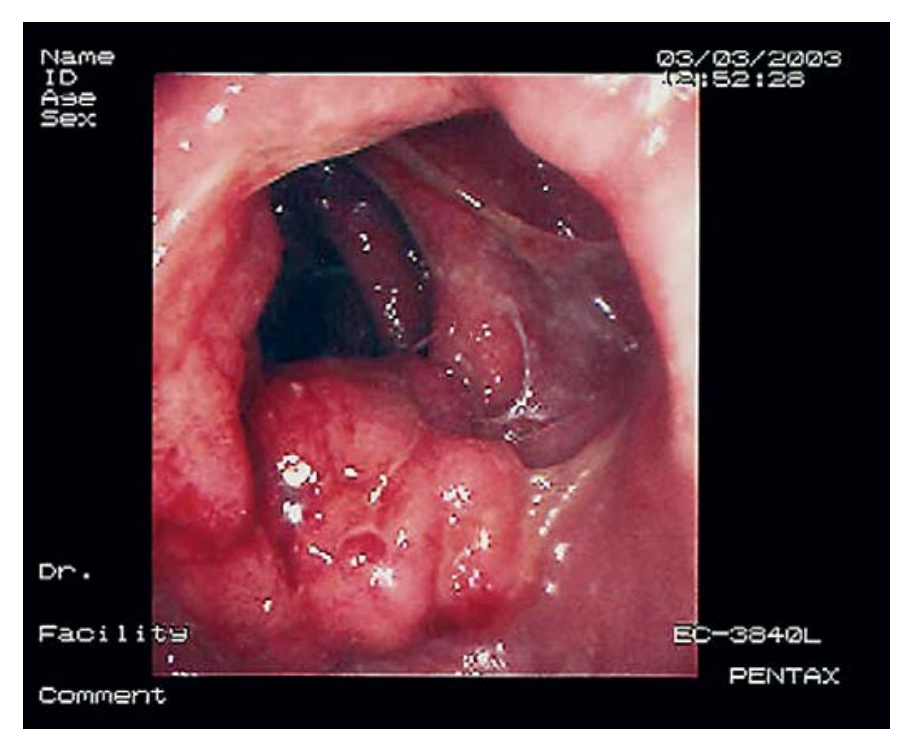

Fig. 1. Lesion at splenic flexure.

is becoming increasingly common but even with this technique an accurate distinction is often not possible [5]. Using this technique, Togashi et al. [5] reported a diagnostic accuracy of neoplastic lesions (sensitivity) of $92 \%$ and that of non-neoplastic lesions (specificity) of $73.3 \%$ with an overall diagnostic accuracy of $88.4 \%$.

Computed tomography (CT) scan plays an important role in the evaluation of patients with suspected colonic inflammation and is often used in addition to colonoscopy in the pre-operative staging of colonic cancers. With high-resolution, thin-section imaging of the gastrointestinal tract, better assessment of both the intraluminal and extraluminal components of colonic disease is

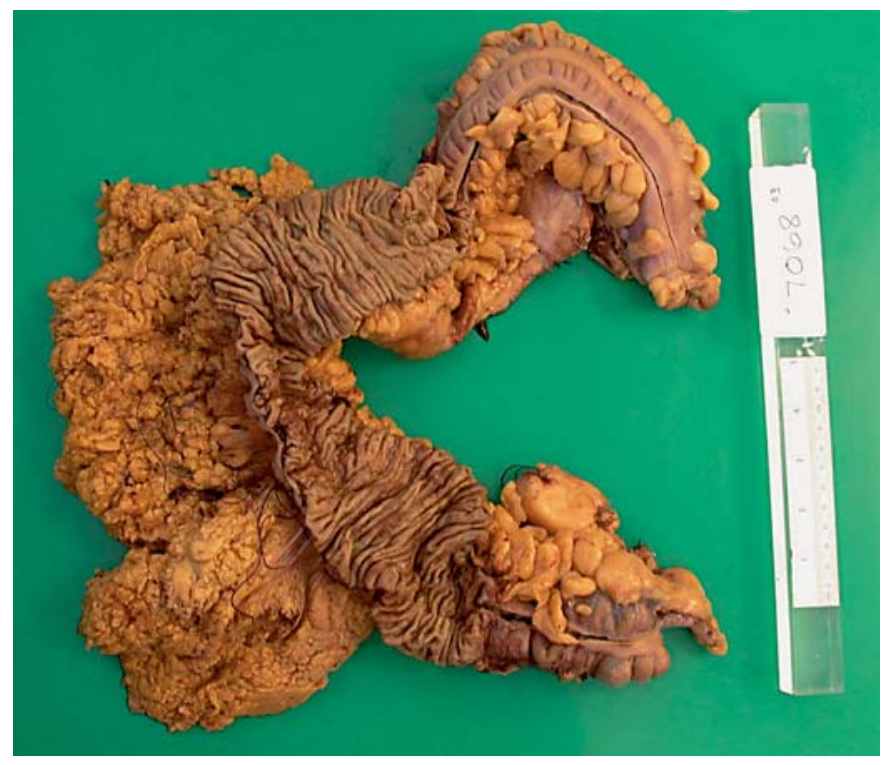

Fig. 2. Macroscopic appearance of the resected colon.

now possible [6]. Pseudopolyps which represent tags of mucosa that have been partially detached during the active episode of ulcerative colitis and remain as projections after healing of ulcers are well recognized; however, a confluence of inflammatory polyps mimicking a cancer as shown in figure 1 with surrounding areas of normal looking mucosa is rare. The above-described case is an unusual example of how a lesion of ulcerative colitis can appear macroscopically frankly malignant but still be benign on histology and we believe that it is important for endoscopists to be aware of such lesions which could pose a diagnostic challenge.

\section{References}

Dig Surg 2005;22:149-150
1 Chutkan RK, Scherl E, Waye JD: Colonoscopy in inflammatory bowel disease. Gastrointest Endosc Clin N Am 2002;12:463-483.

2 Lee SD, Cohen RD: Endoscopy in inflammatory bowel disease. Gastroenterol Clin N Am 2002;31:119-132.

3 Taguchi Y, Miyaoka M, Saito T: Endoscopic diagnosis of ulcerative colitis. Nippon Rinsho 1999;57:2453-2456.

4 Orlandi F, Brunelli E, Feliciangeli G, et al: Observer agreement in endoscopic assessment of ulcerative colitis. Ital J Gastroenterol Hepatol 1998;30:539-541.
5 Togashi K, Konishi F, Ishizuka T, Sato T, Senba S, Kanazawa K: Efficacy of magnifying endoscopy in the differential diagnosis of neoplastic and non-neoplastic polyps of the large bowel. Dis Colon Rectum 1999;42:16021608.

6 Jacobs JE, Birnbaum BA: CT of inflammatory disease of the colon. Semin Ultrasound CT MR 1995;16:91-101. 